\title{
Impact of Lifestyle Modification Module on Adherence to Therapeutic Regimen of Children and Adolescents with Beta Thalassemia Major
}

\author{
Rahma Abdel Aziz ${ }^{1}$, Safy Al Rafay ${ }^{2}$, Randa M. Matter ${ }^{3}$, Salma El Hassan ${ }^{4}$ \\ ${ }^{1}$ Researcher, ${ }^{2,}{ }^{4}$ Professor of Pediatric Nursing, Pediatrics Nursing Department, Ain Shams University, \\ ${ }^{3}$ Professor of Pediatric Medicine, Faculty of Medicine, Ain Shams University, Cairo, Egypt
}

\begin{abstract}
Healthy lifestyle behaviors are important for thalassemic children and adolescents to prevent disease-related complications and improve quality of life. This study aimed to evaluate the effect of lifestyle modification module on adherence of children and adolescent suffering from beta-thalassemia major. Design: A quasiexperimental design was utilized to conduct the study. Sampling: A purposive sample comprised of 80 children \& adolescents with beta thalassemia major. Tools: I-Interviewing questionnaire, II-Children adherence tools: It was used to assess children and adolescents' adherence with: (a) Medication (Morisky), (b) Therapeutic regimen (diet, physical exercise, and follow up). (c) Levels of perceived stress, (d) Sleep quality domains and developed intervention lifestyle modifications module.
\end{abstract}

Results: This study revealed that more than three quarter had satisfactory knowledge about ß-TM post lifestyle modification module implementation and the majority of children and adolescents with $\beta$-TM were adherent to taking medicines yesterday post module implementation.

Conclusion: There were significant improvements of knowledge and adherence of the studied children and adolescents with B-TM to therapeutic regimen post the lifestyle modification module application and there were positive correlations between all variables of the studied children and adolescents with ß-TM.

Keywords: Children-Adolescents-Adherence-Therapeutic Regimen-Beta-thalassemia major.

\section{Introduction}

Beta-thalassemia major ( $(3-\mathrm{TM})$ is the most common hemoglobin disorder in the world and thalassemia major stand among the most severe forms ${ }^{(1)}$. Despite the life-saving nature of long-term blood transfusion, iron toxication due to dysregulated cellular iron metabolism is the leading cause of prolonged complications in children and adolescents with $B-\mathrm{TM}^{(2)}$.

A healthy lifestyle is important for everyone. For children and adolescents living with $\beta-T M$, is

\footnotetext{
Corresponding Author:

Rahma Abdel Aziz

Researcher, Pediatric Nursing, Pediatrics Nursing Department, Ain Shams University, Cairo, Egypt e-mail: rahmapediatric@yahoo.com
}

especially important to know that a healthy lifestyle means "managing the disorder", as well as making healthy choices. Other healthy choices a children and adolescents with thalassemia should consider include keeping vaccinations up-to-date, eating nutritious meals, exercising, and developing positive relationships ${ }^{(3)}$.

Hematologic nurse plays an important role in thalassemia management. Thus, facilitating the children care. Pediatric nurse for the children $\&$ adolescents with ß-TM must have a basic understanding of the disease (4).Clearly, nursing assessment should be done based on subjective and objective data to formulate the nursing diagnosis for the particular child and to implement nursing interventions ${ }^{(5)}$.

Beta thalassemia major is a major public health problem in Egypt with particularly high incidence due to strong cultural preference for consanguineous 
marriages $^{(\boldsymbol{6})}$. It has been estimated that 1000 children out of 1.5 million live births are born annually with thalassemia major; in multicenter studies, the carrier rate in Egypt was reported to range from 5.3 to $\geq 9 \%$ and a gene frequency of $0.03^{(7-9)}$.

\section{The aim of the study:}

This study aims to evaluate the effect of lifestyle modification module on adherence of children and adolescent suffering from beta-thalassemia major, through the following:

1. Assessing children and adolescents knowledge about B-TM.

2. Assessing adherence to therapeutic regimen of children and adolescents with B-TM.

3. Developing and implementing lifestyle modification module for children and adolescents with $\beta-T M$.

4. Evaluating the effect of lifestyle modification module on children and adolescents knowledge and adherence to therapeutic regimen.

\section{Research Hypothesis:}

The implementation of lifestyle modification module will affect positively on knowledge and adherence of children and adolescents with beta-thalassemia major to therapeutic regimen.

\section{Research Design:}

A quasi- experimental design was utilized to conduct the study.

\section{Subjects and Method}

Technical design: The technical design was included research setting, subjects and tools for data collection.

Research Setting: This study conducted at Hematology Outpatient Clinics in Children's Hospital affiliated to Ain Shams University which found in the $4^{\text {th }}$ floor. There is a caravan for blood transfusion in the ground floor. In addition to 3 inpatients wards in the $2^{\text {nd }}$ floor in the mentioned hospital.

Research Subjects: A purposive sample of children and adolescents was selected according to certain inclusion criteria. The sample size was determined statistically by power analysis considering the total number of $\beta$-TM children and adolescents in the previously mentioned setting along 2 years from 2015 till 2017. Accordingly, the sample size was 80 children and adolescents.

\section{Inclusion Criteria:}

The study subject was selected according to the following inclusion criteria:

1. Children and adolescents with B-TM aged 10 years to 18 years.

2. Children and adolescents have long duration of ß-TM (9 years \& more).

\section{Tools for data collection:}

Data was collected using the following Tools:

I- Pre designed questionnaire: pre/post module: It was developed in a simple Arabic language by the researcher after reviewing the related literatures and reviewed by supervisors; it was consisted of three parts:

Part 1: It concerned with characteristics of the study subjects, as follows:

a. Characteristics of the studied children and adolescents including: Age, gender, education level, ranking and residence.

b. Characteristics of caregivers including: Relation, age, level of education and working.

Part 2: It concerned with knowledge of the children and adolescents about B-TM, it composed of 26 questions to assess level of knowledge of the children and adolescents regarding $\beta-\mathrm{TM}$.

Part 3: History of studied children and adolescents regarding $\beta-\mathrm{TM}$.

Part 4: It concerned with evaluating informational needs of studied children and adolescents about $\beta-\mathrm{TM}$ which composed of (12) questions.

II - Children adherence tools: The following tools were used to assess children and adolescents' adherence with: (a) Medication (Morisky), (b) Therapeutic regimen (diet, physical exercise, and follow up). (c) Levels of perceived stress, (d) Sleep quality domains.

(a) Morisky Medication Adherence Scale (MMAS) - Revised: It was adapted from Morisky et al. ${ }^{(10)}$ and modified by the researcher to assess the children adherence toward medication regimen; it consisted of 8 questions. 
III - Perceived Stress Scale (PSS): It was adapted from Cohen, Kamarck \& Mermelstein ${ }^{(11)}$ and modified by the researcher to assess the studied children and adolescents' levels of stress. The scale consisted of 10 questions.

IV-Sleep Quality Scale (SQS): It was adopted from Yi, Shin \& Shin ${ }^{(12)}$ and modified by the researcher to assess the studied children and adolescents sleep quality. It consisted of 28 items, the SQS evaluates six domains of sleep quality: (1) daytime symptoms, (2) restoration after sleep, (3) problems initiating, (4) maintaining sleep, (5) difficulty waking and (6) sleep satisfaction.

Part 5: Effect of the disease on daily living activities of the studied children and adolescents which composed of (10) statements.

\section{Operational Design:}

Field Work: The actual field work was carried out over a period of 9 months from beginning of January 2019 up to the end of September 2019. The researcher was available in the study setting 4 hours for 2 days/ week by rotation according to children and adolescents with $\beta-T M$ appropriate time. The actual field work was divided into four phases:

1-Assessment phase: ( 2 months): In this phase, the researcher used the constructed tools for collecting data related to knowledge of children and adolescents' about ß-TM (pre-test).

2-Planning phase: (1 month): The module was designed on the light of the determined objectives and literature review which was modified to meet the actual children and adolescents needs.

3-Implementing phase: (4 months): At the beginning the researcher disseminated the lifestyle modification module and explained to the children and adolescents how to use the module. The researcher was available 2 days (Saturday and Sunday/week, 4 hours a day.

4-Evaluating phase: (2 months): The same tools were used after the implementation phase of lifestyle modification module an indicator to determine the level of children and adolescents' knowledge.

Validity: Tools of this study were judged by a panel of seven expertise and they were professors of pediatric nursing. The necessary modifications were done according to experts' opinion to ensure validity of the content.

Reliability: The reliability was conducted for the developed tools. The reliability was scaled as follows: $<0-0.25$ weak reliability, $0.25-0.75$ moderate reliability, $0.75-<1$ strong reliability and 1 is optimum. The reliability for this questionnaire was 0.81 .

Exploratory phase: A pilot study was carried out during November 2018 involved 10\% (8 of children and adolescents with beta thalassemia major) of the total study sample. The result of the data obtained from the pilot study helped in removing of some repeated questions related to knowledge to avoid duplication of questions and then all children involved in the pilot study were included of the study sample.

Administrative design: Approval was obtained through an issued letter from Dean of Faculty of Nursing, Ain Shams University to the Hospital Director of the previously mentioned settings and the researcher was explaining aim of the study and its expected outcomes.

Statistical Design: The data obtained was organized, analyzed, and presented in the form of tables and figures using the Statistical Package for Social Sciences (SPSS) version 20. Qualitative variables were presented in the form of frequencies and percentages; quantitative variables was presented in the form mean and SD. Qui square and Fishers Exact tests were used to test the significance of results obtained. Statistical significant difference was considered at $\mathrm{P}<0.05$.

\section{Ethical considerations:}

The ethical considerations in the study included the following:

All the gathered data was used for research purpose only. The study sample was informed about the purpose and expected outcomes of the study and they was assured that the study is harmless and their participation is voluntary and they have the right to withdraw from the study at any time and without given any reason. They were assured also that anonymity and confidentiality were guaranteed.

\section{Results}

This study was designed to identify the impact of lifestyle modification module on adherence to therapeutic regimen of children and adolescents with beta thalassemia major. 
Table 1: Distribution of the studied children and adolescents with $B-T M$ according to their characteristics $(n=80)$.

\begin{tabular}{|l|c|c|}
\hline $\begin{array}{l}\text { Characteristics of children \& } \\
\text { adolescents }\end{array}$ & No. & \% \\
\hline Age (years) & 16 & 20 \\
$10<13$ & 34 & 42.5 \\
$13<16$ & 30 & 37.5 \\
$16-18$ & \multicolumn{2}{|c|}{$14.25 \pm 2.84$} \\
\hline Mean \pm SD & \multicolumn{2}{|}{} \\
\hline Gender & 34 & 42.5 \\
Male & 46 & 57.5 \\
Female & & \\
\hline Level of education & 26 & 32.540 \\
Primary & 32 & 27.5 \\
Preparatory & 22 & \\
Secondary & \multicolumn{2}{|l|}{} \\
\hline
\end{tabular}

\begin{tabular}{|l|c|c|}
\hline $\begin{array}{l}\text { Characteristics of children \& } \\
\text { adolescents }\end{array}$ & No. & \% \\
\hline Ranking & 23 & 28.7 \\
First & 16 & 20 \\
Second & 16 & 20 \\
Third & 25 & 31.3 \\
Forth & & \\
\hline Residence & 30 & 37.5 \\
Urban & 50 & 62.5 \\
Rural & \\
\hline
\end{tabular}

Table (1): shows that, more than two fifth(42.5\%) of the studied children aged from 13 to $<16$ years with a mean age $14.25 \pm 2.84$ years and more than half $(57.5 \%)$ of them were females. Moreover, this table reveals that, two fifth $(40 \%)$ of the studied children had preparatory education, less than two thirds $(62.5 \%)$ of them were from rural areas.

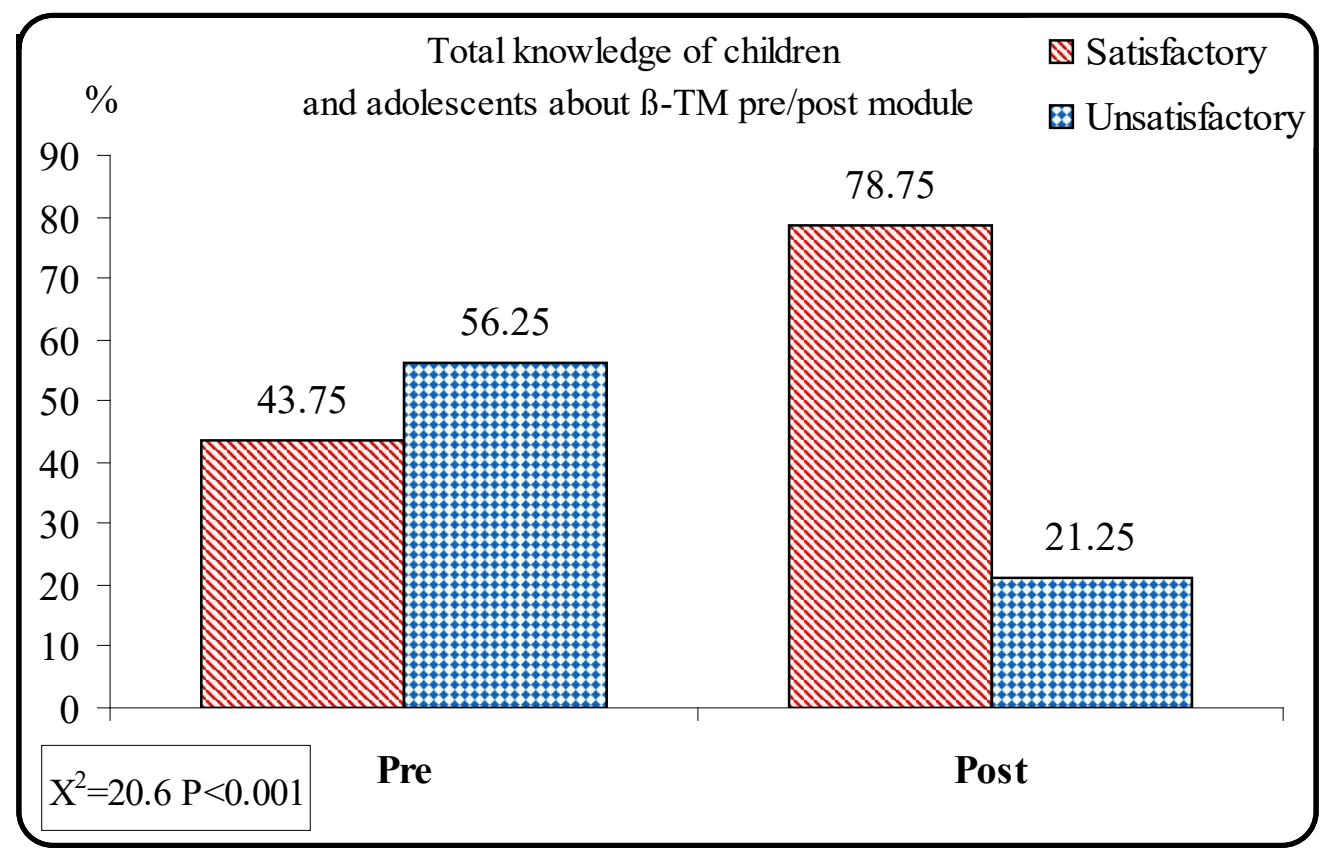

Figure 1: Percentage distribution of the studied children and adolescents with $\beta$-TM according to their total knowledge about beta thalassemia major pre/post $\operatorname{module}(n=80)$.

Figure (1) shows that more than three quarter (78.75\%) had satisfactory knowledge about $ß-\mathrm{TM}$ post lifestyle modification module implementation compared to pre module implementation the proportion was more than two fifth $(43.75 \%)$ and this reflected statistical significant difference between pre and post lifestyle modification module implementation $\mathrm{P}$ - value $<0.001$. 
Table 2: Distribution of the studied children and adolescents with B-TM according to their adherence to medication regimen pre/post module $(n=80)$.

\begin{tabular}{|c|c|c|c|c|c|c|c|c|c|c|}
\hline \multirow{3}{*}{ Adherence to Medication regimen } & \multicolumn{4}{|c|}{ Pre } & \multicolumn{4}{|c|}{ Post } & \multirow{2}{*}{\multicolumn{2}{|c|}{ Chi-square }} \\
\hline & \multicolumn{2}{|c|}{ Yes } & \multicolumn{2}{|c|}{ No } & \multicolumn{2}{|c|}{ Yes } & \multicolumn{2}{|c|}{ No } & & \\
\hline & No. & $\%$ & No. & $\%$ & No. & $\%$ & No. & $\%$ & $\mathbf{X}^{2}$ & P-value \\
\hline Sometimes forget taking medicines & 55 & 68.8 & 25 & 31.2 & 77 & 96.3 & 3 & 3.8 & 20.952 & $<0.001 * *$ \\
\hline $\begin{array}{l}\text { Over the past two weeks, one dose of } \\
\text { medicines not taken }\end{array}$ & 56 & 70 & 24 & 30 & 76 & 95 & 4 & 5 & 17.316 & $<0.001 * *$ \\
\hline $\begin{array}{l}\text { Ever cut back or stopped taking medicines } \\
\text { without telling physician }\end{array}$ & 50 & 62.5 & 30 & 37.5 & 79 & 98.8 & 1 & 1.2 & 33.648 & $<0.001 * *$ \\
\hline $\begin{array}{l}\text { Sometimes forget to bring medicine when } \\
\text { travel or leave home }\end{array}$ & 49 & 61.3 & 31 & 38.8 & 78 & 97.5 & 2 & 2.5 & 32.107 & $<0.001 * *$ \\
\hline Taking medicines yesterday & 28 & 35 & 52 & 65 & 1 & 1.2 & 79 & 98.8 & 30.703 & $<0.001 * *$ \\
\hline $\begin{array}{l}\text { Sometimes stop taking medicine when } \\
\text { feeling like the disease's symptoms are } \\
\text { under control }\end{array}$ & 41 & 51.3 & 39 & 48.8 & 75 & 93.7 & 5 & 6.3 & 36.238 & $<0.001 * *$ \\
\hline $\begin{array}{l}\text { Felling hassled about sticking to the } \\
\text { treatment plan }\end{array}$ & 33 & 41.3 & 47 & 58.8 & 76 & 95 & 4 & 5 & 53.218 & $<0.001 * *$ \\
\hline \multicolumn{11}{|c|}{ Often have difficulty remembering to talked medicines } \\
\hline Never & 9 & 11.3 & 71 & 88.8 & 67 & 83.8 & 13 & 16.3 & \multirow{3}{*}{83.123} & \multirow{3}{*}{$<0.001 * *$} \\
\hline Once & 17 & 21.3 & 63 & 78.8 & 13 & 16.3 & 67 & 83.8 & & \\
\hline Sometimes & 54 & 67.5 & 26 & 32.5 & 0 & 0.0 & 80 & 100.0 & & \\
\hline
\end{tabular}

Not significant $\mathrm{p}>0.05 *$ Significant $\mathrm{p}<0.05 * *$ Highly significant $\mathrm{p}<0.001$

Table (2): clarifies that the more than half (52\%) of studied children and adolescents with B-TM were adherent to taking medicines yesterday pre lifestyle modification module implementation module compared to post module implementation the percentage was the majority $(98.8 \%)$. This table reflect that there were highly statistical significant difference as $\mathrm{P}$ - value $<0.001$.

Table 3: Distribution of the studied children and adolescents with B-TM according to their adherence to diet regimen pre/post module $(\mathrm{n}=\mathbf{8 0})$.

\begin{tabular}{|c|c|c|c|c|c|c|c|c|c|c|}
\hline \multirow{3}{*}{ Adherence to diet regimen } & \multicolumn{4}{|c|}{ Pre } & \multicolumn{4}{|c|}{ Post } & \multirow{2}{*}{\multicolumn{2}{|c|}{ Chi-square }} \\
\hline & \multicolumn{2}{|c|}{ Yes } & \multicolumn{2}{|c|}{ No } & \multicolumn{2}{|c|}{ Yes } & \multicolumn{2}{|c|}{ No } & & \\
\hline & No. & $\%$ & No. & $\%$ & No. & $\%$ & No. & $\%$ & $\mathrm{X}^{2}$ & P-value \\
\hline Eat meals regularly & 42 & 52.5 & 38 & 47.5 & 64 & 80 & 16 & 20 & 13.529 & $<0.001 * *$ \\
\hline Drink milk and dairy products & 41 & 51.2 & 39 & 48.8 & 69 & 86.3 & 11 & 13.7 & 22.807 & $<0.001 * *$ \\
\hline Eat wheat, oats, rice and maize & 24 & 30 & 56 & 70 & 58 & 72.5 & 22 & 27.5 & 28.918 & $<0.001 * *$ \\
\hline Drink tea with meals & 42 & 52.5 & 38 & 47.5 & 79 & 98.7 & 1 & 1.3 & 46.417 & $<0.001 * *$ \\
\hline $\begin{array}{l}\text { Replacing high red meat with iron with } \\
\text { white meat }\end{array}$ & 66 & 82.5 & 14 & 17.5 & 72 & 90 & 8 & 10 & 1.897 & 0.168 \\
\hline $\begin{array}{l}\text { Eat foods that contain vitamin } \mathrm{C} \text { in a } \\
\text { small amount }\end{array}$ & 41 & 51.2 & 39 & 48.8 & 67 & 83.75 & 13 & 16.25 & 19.259 & $<0.001 * *$ \\
\hline $\begin{array}{l}\text { Refrain from eating foods that contain } \\
\text { iron }\end{array}$ & 66 & 82.5 & 14 & 17.5 & 76 & 95 & 4 & 5 & 6.260 & $0.012 *$ \\
\hline $\begin{array}{l}\text { The appetite is affected after blood } \\
\text { transfusion and treatment }\end{array}$ & 39 & 48.7 & 41 & 51.3 & 48 & 60 & 32 & 40 & 2.041 & 0.153 \\
\hline
\end{tabular}

Not significant $\mathrm{p}>0.05 *$ Significant $\mathrm{p}<0.05 * *$ Highly significant $\mathrm{p}<0.001$ 
Table (3): shows that the more than fifty $(52.5 \%)$ of the studied children and adolescents with B-TM were adherent to drink tea with meals pre lifestyle modification module implementation, in contrast this proportion increased to the majority $(98.7 \%)$ were adherent respectively post module implementation. This reflected highly statistical significant difference pre/post lifestyle modification module implementation.

Table 4: Distribution of the studied children and adolescents with B-TM according to their adherence to physical exercise regimen pre/post module $(n=80)$.

\begin{tabular}{|c|c|c|c|c|c|c|c|c|c|c|}
\hline \multirow{3}{*}{ Adherence to physical exercise } & \multicolumn{4}{|c|}{ Pre } & \multicolumn{4}{|c|}{ Post } & \multirow{2}{*}{\multicolumn{2}{|c|}{ Chi-square }} \\
\hline & \multicolumn{2}{|c|}{ Yes } & \multicolumn{2}{|c|}{ No } & \multicolumn{2}{|c|}{ Yes } & \multicolumn{2}{|c|}{ No } & & \\
\hline & No. & $\%$ & No. & $\%$ & No. & $\%$ & No. & $\%$ & $X^{2}$ & P-value \\
\hline Practice exercises regularly & 40 & 50 & 40 & 50 & 50 & 62.5 & 30 & 37.5 & 2.540 & 0.111 \\
\hline Walking daily & 48 & 60 & 32 & 40 & 57 & 71.3 & 23 & 28.8 & 2.244 & 0.134 \\
\hline Take a break in case of fatigue & 56 & 70 & 24 & 30 & 73 & 91.3 & 7 & 8.8 & 11.563 & $<0.001 * *$ \\
\hline $\begin{array}{l}\text { Feeling any symptoms after walking } \\
\text { exercise }\end{array}$ & 48 & 60 & 32 & 40 & 68 & 85.0 & 12 & 15.0 & 12.539 & $<0.001 * *$ \\
\hline $\begin{array}{l}\text { After exercise feeling good mood and } \\
\text { enjoy a deep and quiet sleep }\end{array}$ & 48 & 60 & 32 & 40 & 62 & 77.5 & 18 & 22.5 & 5.702 & $0.017^{*}$ \\
\hline $\begin{array}{l}\text { Cannot participate in school activities } \\
\text { because of the shyness of the change in } \\
\text { form due to illness in front of classmates }\end{array}$ & 32 & 40 & 48 & 60 & 67 & 83.8 & 13 & 16.3 & 32.456 & $<0.001 * *$ \\
\hline $\begin{array}{l}\text { Get bored practice simple exercises to } \\
\text { renew activity }\end{array}$ & 48 & 60 & 32 & 40 & 63 & 78.8 & 17 & 21.3 & 6.619 & $0.010 *$ \\
\hline $\begin{array}{l}\text { Exercise is often the only way to remove } \\
\text { stress }\end{array}$ & 56 & 70 & 24 & 30 & 64 & 80.0 & 16 & 20.0 & 2.133 & 0.144 \\
\hline
\end{tabular}

Not significant $\mathrm{p}>0.05 *$ Significant $\mathrm{p}<0.05 * *$ Highly significant $\mathrm{p}<0.001$

Table (4): reveals that less than three fourths (70\%) of studied children and adolescents with B-TM were adhered to take a break in case of fatigue pre lifestyle modification module implementation, in contrast this proportion increased to the majority $(91.3 \%)$. As well as less than two thirds $(60 \%)$ of the studied children and adolescents with B-TM hadn't participate in school activities because of the shyness of the change in form due to illness in front of classmates pre lifestyle modification module implementation, vice versa post module implementation the percentage was decreased to the few $(16.3 \%)$ of them with P- value $<0.001 * *$ post module implementation. This table reflected highly statistical significant difference pre/post lifestyle modification module implementation.

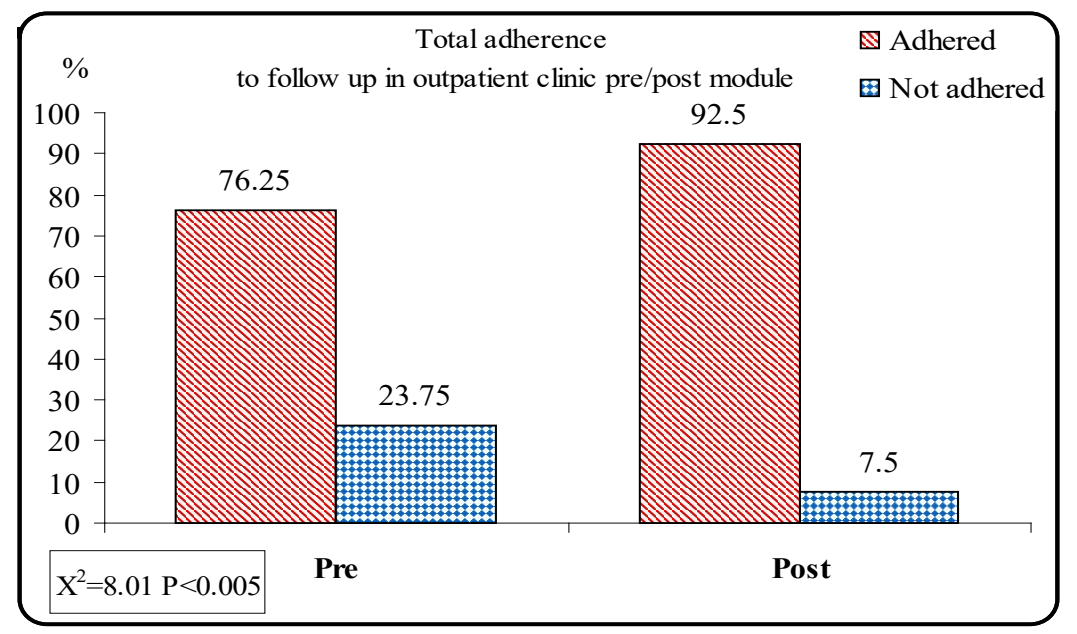

Figure 2: Percentage distribution of the studied children and adolescents with B-TM according to their total adherence to follow up in outpatient clinic pre/post module $(n=80)$. 
Figure (2) indicates that the majority (92. 5\%) were adherent to follow up regimen post lifestyle modification module implementation compared to more than half $(76.25 \%)$ pre module implementation and this reflected statistical significant difference between pre and post lifestyle modification module implementation $\mathrm{P}$ - value $<0.001$.

\section{Discussion}

A healthy lifestyle is a maintaining control over all lifestyle behaviors that might influence one's health and well-being and organizing daily life activities by choosing appropriate behaviors of their own accord ${ }^{(\mathbf{1 3})}$. Healthy lifestyle behaviors and activities primarily include spiritual development, personal health responsibility, physical activity, diet, interpersonal support, and stress management ${ }^{(14-15)}$.

Beta thalassemia major has a negative impact on the lifestyle due to the effects of the disease and its treatment, not only affecting children's physical function but also their social, emotional, and school function, leading to impaired lifestyle. Similar conditions also affected their family members, such as sadness, disappointment, hopelessness, stress, depression, and anxiety about their children's lives ${ }^{(\mathbf{1 6})}$.

The Role of the hematologic nurse, to give the child and adolescent time to express feelings and fears to be there' for the child and adolescent, to support and encourage, to reassure and to calm. Early social services consultation to address financial and social issues is mandatory ${ }^{(17)}$.

The findings of the present study showed that two fifth of the studied children were preparatory school. This finding disagreement with Hisam et al. ${ }^{(\mathbf{1 8})}$ and reported that regarding education status of studied subject having more than two fifth primary educations. Moreover, this finding was not supported byAli, ElBilsha \& Mohamed, ${ }^{(19)}$ who carried out a study entitled "Coping Strategies among Children with Thalassemia" and mentioned that $4.3 \%$ of studied thalassemic children not entered school.

The results of the present study revealed that slightly less than two thirds of the studied children and adolescents from rural area. This could be attributed to the fact that rural areas face a problem of deficient quality health care services and health care providers. This shed the light on the importance of strengthening the rural areas with proper health care services in order to fulfill their residences needs of effective and efficient health services. The same results could be attributed to the high prevalence of poverty and illiteracy among rural population. This finding was in accordance with Gharaibeh et al., (20) who mentioned that less than two thirds of children from rural area. However, these findings were similar to a study done byAbusaad $\&$ Sarhan, (21) this study revealed that most of studied children were from rural areas.

As regard to total knowledge about B-TM of the studied children and adolescents, the results of the present study illustrated that more than three quarters had satisfactory knowledge about B-TM post lifestyle modification module implementation compared to less than half of them pre module implementation and this reflected statistical significant improvement between pre and post lifestyle modification module implementation (P-value $<0.001$ ). This may be attributed to the absence of in-service training program in the hospital and there was no motivation for the children and adolescents to improve their knowledge and increased awareness of children and adolescents about B-TM after module implementation.

These findings came in line with that of Abu Samra et al. ${ }^{\text {(22) }}$ reported that there was an extremely significant statistical improvement in relation to the studied children's knowledge score pre-program and post-program implementation. Previously, this result comes in accordance with thatArmeli et al., ${ }^{(23)}$ found that B-thalassemia education program in Italy appear to have dramatically increased awareness of the disorder. Recently, this finding was in agreement withZaghamir et al. ${ }^{\text {(24) }}$ reported that there was statistically significant improvement of children's knowledge. Subsequently, statistically significant improvement of children's quality of life at follow up compared with pre-intervention phase. In the same context Bazpour et al., ${ }^{(25)}$ statedthat before intervention the mean of knowledge score was in the weak level in the two groups but immediately after and a month after intervention it reached to the good level in the experimental group.

Regarding medication regimen, the results of the current study revealed that the more than half of studied children and adolescents were adherent for taking medicines yesterday pre lifestyle modification module implementation module compared to post module implementation the percentage were the majority and 
this reflect that there were highly statistical significant improvement $(\mathrm{P}$-value $<0.001)$. It could be due to the children and adolescents recognition of the dangerous complications of medication dose forgetting after module implementation. This results was in accordance to those of Komatsu, Yagasaki \& Yoshimura, ${ }^{(26)}$ reported that the majority of children with B-TM adherence to medication regimen. In general patients are considered to be adherent if the $\geq 80 \%$ of prescribed medication is taken timely and at an appropriate dose without missing dose or extra dose. In the same context. Aboelela et

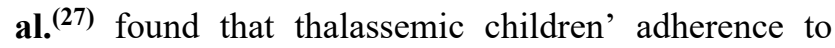
iron chelation therapy were significantly improved after implementation of the multidimensional intervention.

Concerning adherence to diet regimen, the findings of the current study revealed that more than three fourths of studied children and adolescents were adhered to diet regimen post lifestyle modification module implementation compared to more than half pre module implementation and this reflected statistical significant improvement between pre and post lifestyle modification module implementation. It could be due to that the children and adolescents do not adhered to diet regimen because they are not aware of the importance of its following and after implementing the module their awareness increased with respect to following adherence to diet regimen. As well as this result agree with that of Bazpour et al. ${ }^{(25)}$ who reported that significant effect in the experimental group immediately after and a month after intervention on nutrition adherence were increased in the post-test taken from the experimental group.

Concerning study of children and adolescents adherence to physical exercise, the findings of the current study reported that less than three fourths of studied children and adolescents were adhered to take a break in case of fatigue pre lifestyle modification module implementation, in contrast this proportion increased to the majority and this reflected highly statistical significant improvement pre/post lifestyle modification module implementation. This findings was in accordance with that ofElalf et al. ${ }^{(28)}$ reported that the studied children and adolescents took a break when felt fatigue and limit physical activities and their exercise capacity because many patients did not come regularly for blood transfusion and thus were suffering from anemic consequences and the presence of physical complications.

Regarding total adherence to follow up, the findings of the current study revealed that the majority were adhered to follow up regimen post lifestyle modification module implementation compared to more than half pre module implementation and this reflected statistical significant improvement between pre and post lifestyle modification module implementation. This finding was supported by Biswas et al. ${ }^{\text {(29) }}$ reported that caregivers of thalassemia patients had significantly higher and regular visit to the hospital.

\section{Conclusion}

Based on results of the current study, it can be concluded that there were significant improvements of knowledge and adherence of the studied children and adolescents with $B-T M$ to therapeutic regimen post the lifestyle modification module application and there were positive correlations between all variables of the studied children and adolescents with ß-TM.

\section{Conflict of Interest: Nil}

\section{Source of Funding: Self}

\section{References}

1. Abu-Muammar A. Assessment of the quality of life among thalassemia patients in the Gaza strip 2020. International J of Nursing and Health Science2020; 7(1): 21-28.

2. Chuansumrit A, Pengpis P, Mahachoklertwattana P, Sirachainan N, Poomthavorn P, Sungkarat W, Kadegasem $P$, KhlairitP and Wongwerawattanakoon P. Effect of Iron chelation therapy on glucose metabolism in non-transfusion-dependent thalassaemia. Acta Haematol2017; 137(1): 20-6. DOI: https://doi.org/10.1159/000450673

3. Centers for Disease Control and Prevention [CDC]. Content source: National center on birth defects and developmental disabilities, centers for disease control and prevention. Available at: https://www. cdc.gov/ncbddd/thalassemia/living.html.2020.

4. Bryant R. Chapter 24 the child with hematologic or immunologic dysfunction. Wong's Essentials of Pediatric Nursing. Hocknberry, M., Wilison, D. $\&$ Rogers, C. $10^{\text {th }}$ ed., Elesvier. Canda2017; 800. ISBN: 9780323353168.

5. Datta P.Pediatric Nursing (As per INC Syllabus) Paperback - chapter 18, childhood blood dyscrasias. $4^{\text {th }}$ ed., Jaypee Brothers Medical Publishers, London2018; 301-303.ISBN:9789352701186. 
6. Adly A,Ebeid F. Cultural preferences and limited public resources influence the spectrum of thalassemia in Egypt. J PediatrHematol Oncol2015; 37(4):281-284.

7. Sherief L, Abd El-Salam S, Kamal N, El Safy, O, Almalky, M,AzabS,MorsyH and GhariebA. Nutritional biomarkers in children and adolescents with beta-thalassemia-major: an Egyptian center experience. Biomed Res Int2014; 261761. DOI: 10.1155/2014/261761.

8. El-Shanshory M, Hagag A, Shebl S, et al. Spectrum of beta globin gene mutations in Egyptian children with $\beta$-thalassemia. Mediterr J Hematol Infect Dis2014; 6(1):e2014071.

9. Elmezayen A, Kotb S, Sadek N and Abdalla E. $\beta$-Globin mutations in Egyptian patients with $\beta$-thalassemia. Lab Med 2015; 46(1):8-13. DOI: 10.1309/LM1AYKG6VE8MLPHG.

10. Morisky D, Ang A, Krousel-Wood M and Ward H. Predictive Validity of a Medication Adherence Measure in an Outpatient Setting. JCH2010; 10(5):348-354.

11. Cohen S, Kamarck T andMermelstein R. A global measure of perceived stress. $\mathrm{J}$ of Health and Social Behavior1983; 24(4): 385-396. https://doi. org/10.2307/2136404.

12. Yi H, Shin K and Shin C. Development of the sleep quality scale. J of Sleep Research2006; 15(3): 309316.

13. Altay $B$, Çavuşoğlu $F$ andGüneştaş İ. Healthy life behaviors of nurses in a medicine faculty hospital and related factors. DokuzEylül University Nursing Faculty E-J 2015; 8(1): 12-18. ISSN: 2149-0333.

14. Kim H, Choi-Kwon S, Kim H, Park Y and Koh C. Health-promoting lifestyle behaviors and psychological status among Arabs and Koreans in the United Arab Emirates, Research in Nursing \& Health2015; 38, 133-141.DOI: 10.1002/nur.21644

15. Yi M, Kim J. Factors influencing health promoting behaviors in Korean breast cancer survivors, European J of Oncology Nursing2013; 17(2): 138145.DOI:10.1016/j.ejon.2012.05.001

16. Grabmann C,Schermuly C. A literature review on negative effects of coaching-what we know and what we need to know. Coaching Internationally Journal of theory, Research, and practice2019; 12 (1): Available at: http://doi. org/10.1080/17.

17. Kwiatkowski J. Chapter 489, Part xx Disease of the blood. Nelson text book of pediatrics. $21^{\text {th }}$ ed., Kliegman, R., St Geme., J., Blum, N., Shah, S., Tasker, R. \& Wilson, K. Elsevier, Canada2020; 2554-2557.ISBN: 9780323529501.

18. Hisam A, Khan N,Tariq N,IrfanH,ArifB and NoorM. Perceived stress and monetary burden among thalassemia patients and their caregivers Pak J Med Sci2018; 34(4): 901-906.

19. Ali A, El-Bilsha $\mathrm{M}$ and Mohamed A Coping strategies among children with thalassemia IOSR J of Nursing and Health Science (IOSR-JNHS) 2018; e- ISSN: 2320-1959.p- ISSN: 2320-1940 7 (2): Ver. X, PP 50-58 www.iosrjournals.org.

20. Gharaibeh H, Barqawi M, Al-Awamreh $\mathrm{K}$ and $\mathrm{Al}$ Bashtawy M. Clinical burdens of $\beta$-thalassemia major in affected children. J PediatrHematol Oncol2018; 40(3): 182-187. DOI: 10.1097/ MPH.0000000000001104

21. Abusaad $\mathrm{F}$ andSarhan $\mathrm{M}$. Exercise training program and telenursing effects on depression and fatigue level in b- thalathemia major children. American J of Nursing Science2016; 5(5): 191-200 http:// www.sciencepublishinggroup.com/j/ajns DOI: 10.11648/j.ajns.20160505.14.

22. Abu Samra O, Auda W, Kamhawy H and AlTonbary Y. Impact of educational programme regarding chelation therapy on the quality of life for B-thalassemia major children. Hematology2015; 20(5): 297-303.

23. Armeli C, Robbins S andEunpu D. Comparing knowledge of beta thalassemia in samples of Italians, Italian-Americans and non ItalianAmericans. J Genet Couns2005; 14(5):365-76.

24. Zaghamir D, El-Kazaz R, Khalil A andElmazahy M. Impact of Educational Program about Iron Chelation Therapy on the Quality of Life for Thalassemic Children2019;6 (3): 33-49. DOI:10.21608/PSSJN.2019.66511.

25. BazpourM,GheibizadehM,Malehi A and Keikhaei B. Theeffectofatrainingprogrambasedonthe precede-proceed model on lifestyle ofadolescents with beta-thalassemia:a randomized controlledclinical trial. Int JHematolOncol Stem Cell Res2019; 13(1):12-19.

26. Komatsu H, Yagasaki K and Yoshimura K. Current nursing practice for patients on oral chemotherapy: a multicenter survey in Japan. BMC Res Notes2014; 7: 259. http://dx.doi.org/10.1186/1756-0500-7259. 
27. Aboelela E,El-Dakhakhny A,Hesham $M$ and Zain El-Abdeen K.Effect of multidimensional intervention on improving adherence of thalassemic children to iron chelation therapy. Zagazig Nursing J2018; 14 (2): 153-166.

28. Elalfy, M., Farid, M., Labib, J. \& Rezkallah, H. (2014): Quality of life of Egyptian beta thalassemia major children and adolescents: Egyptian $\mathrm{J}$ of hematology; 39(4): 222-226.

29. Biswas B, Naskar N, Basu K, Dasgupta A, Basu Rand Paul B. Malnutrition, its attributes, and impact on quality of life: an epidemiological study among $\beta$-thalassemia major children Korean. J Fam Med 2020; DOI: 10.4082/kjfm.19.0066. 